\title{
Evaluation of the bone morphology around four types of porous metal implants placed in distal femur of ovariectomized rats
}

\author{
Stanislav Bondarenko ${ }^{1 *}$ (D), Nataliya Ashukina', Valentyna Maltseva', Gennadiy Ivanov',
} Ahmed Amine Badnaoui ${ }^{1}$ and Ran Schwarzkopf ${ }^{2}$

\begin{abstract}
Background: To compare structural features of the femoral bone of ovariectomized and non-ovariectomized rats after implantation of porous materials (TANTALUM, CONCELOC, TTM, ATLANT).

Methods: Experiments were carried out on 56 white laboratory female rats aged 6 months. Rats were randomly assigned into groups: sham-operated control group (SH) or ovariectomy group (OVX). Four different commercial implant materials (TTM, CONCELOC, TANTALUM, ATLANT) were placed into the defects (diameter $2.5 \mathrm{~mm}$, depth 3.0 $\mathrm{mm}$ ) in the distal metaphysis of femurs. Rats were sacrificed 45 days after surgery. Histological study was performed and the percentage of the bone area (BA\%) around the implant at a distance of $500 \mu \mathrm{m}$ in the cancellous area was measured.

Results: Formation of mature bone tissue of varying degrees around all of the implants was detected. In OVX rats cancellous bone defect zone was characterized by a high density of osteocytes on the surface. In the SH group, no differences in BA\% among implant materials were found. In OVX rats, the BA\% around ATLANT implants was 1.5time less $(p=0.002)$ than around TANTALUM. The BA\% around the rest of the materials was not statistically different.

Conclusions: Bone formation around the studied porous titanium and tantalum materials in the osteoporosis model was lower than in normal bone. There were differences in bone formation around the different materials in the osteoporosis model, while in the normal bone model, these differences were absent.
\end{abstract}

Keywords: Tantalum, Titanium, Osteoporosis, Animal model, Bone remodeling, Histology

\section{Background}

Total hip arthroplasty (THA) in cases of large acetabular defects and in patients with osteoporotic bone can be difficult. Furthermore, achieving a long-term stable fixation of the acetabular cup is challenging [1-4].

\footnotetext{
* Correspondence: bondarenke@gmail.com

'Dept of Joint Pathology, Sytenko Institute of Spine and Joint Pathology, National Academy of Medical Sciences of Ukraine, 80 Pushkinskaya St, Kharkiv 61024, Ukraine

Full list of author information is available at the end of the article
}

Cement usage for acetabular cup fixation in primary THA has fallen out of favor in recent decades mostly due to increased risk of aseptic loosening in mid and long-term follow-up [5-8]. Biological fixation of highly porous biomaterials in THA plays an important role in long-term survivorship of acetabular implants. A longterm stable fixation of these implants depends largely on the osseointegration of bone tissue into them [9].

Following acetabular component placement, osseointegration depends on both the quality of bone tissue and the properties of the implant surface [10-12]. New

C C The Author(s). 2020 Open Access This article is licensed under a Creative Commons Attribution 4.0 International License, which permits use, sharing, adaptation, distribution and reproduction in any medium or format, as long as you give appropriate credit to the original author(s) and the source, provide a link to the Creative Commons licence, and indicate if changes were made. The images or other third party material in this article are included in the article's Creative Commons licence, unless indicated otherwise in a credit line to the material. If material is not included in the article's Creative Commons licence and your intended use is not permitted by statutory regulation or exceeds the permitted use, you will need to obtain permission directly from the copyright holder. To view a copy of this licence, visit http://creativecommons.org/licenses/by/4.0/. The Creative Commons Public Domain Dedication waiver (http://creativecommons.org/publicdomain/zero/1.0/) applies to the data made available in this article, unless otherwise stated in a credit line to the data. 
highly porous biomaterials were developed to enhance osseointegration and survivorship of acetabular reconstruction [13]. Current, highly porous biomaterials for THA are made of tantalum and titanium (partial use alloy $\mathrm{Ti}_{6} \mathrm{Al}_{4} \mathrm{~V}$ ) [14]. The advantages of porous tantalum are high thermal conductivity and biocompatibility $[15$, 16], and they have been shown to have good survivorship in long-term follow-up [17, 18]. However, according to the Swedish Hip Arthroplasty Registry and the Australian Orthopaedic Association National Joint Replacement Registry data, Trabecular Metal acetabular components in primary THA showed a higher risk for revision compared with other uncemented acetabular cups $[19,20]$.

Current research focuses on porous titanium materials characteristics, as well as their comparison with tantalum implants [21, 22]. Titanium porous implants have low thermal conductivity, high yield strength, and low weight and have been shown to have high survival [23] and lower cost compared to tantalum implants [14]. In a 10-year clinical randomized trial of primary THA, porous tantalum monoblock cups exhibited greater stability and 100\% survivorship compared to porous-coated titanium monoblock cup [22]. In another study using multivariate logistic regression, the authors compared the survival of porous tantalum and porous titanium acetabular components with primary THA at an average of 44.4 months the authors found no difference in outcomes [21].

Bone changes in osteoporosis may cause additional difficulty in acetabular reconstruction as well as increasing the risk of aseptic failure and loosening. Under these conditions, the requirements for implant materials become even more important. In order to study osseointegration and fixation properties, animal models were established for material evaluation [24]. It has been established that osteoporosis can affect the fixation and osseointegration of implants $[25,26]$, in particular, giving the different responses of osteoporotic cortical and trabecular bone to material implantation [27]. Therefore, establishing the structural features of bone tissue around porous implant materials is important for selecting a particular material for use in patients with low bone mineral density.

In an early study, we compared the osseointegration of a tantalum material with titanium in an ovariectomy model, revealing the highest rate of osseointegration with the tantalum material, while the overall rates of osseointegration in animals with osteoporosis were lower than non-osteoporotic animals [28]. As a result of this, we decided to study several available titanium materials on the market, as well as one novel material in a similar experiment to understand the formation and osseointegration of bone around these materials in an osteoporosis model in comparison with a normal bone model.
The aim of this study was to compare structural features of the femoral bone in ovariectomized and nonovariectomized rats after implantation of different porous materials.

\section{Methods \\ Animals}

Experiments were carried out on 56 white laboratory female rats aged 6 months, with an average body weight of $300 \pm 25 \mathrm{~g}$. Rats were randomly assigned to 1 of 2 groups: sham-operated control group $(\mathrm{SH})$ or ovariectomy group (OVX). The study followed the requirements of the European Convention for the protection of vertebrate animals used for experimental and other scientific purposes. The study design was approved by the institution Bioethics Committee (Protocol No. 175 dated 26 February 2018).

\section{Implants}

Four commercially available porous implants were used in this study. The first is TANTALUM-porous Tantalum Trabecular Metal (Zimmer, Warsaw, IN, USA). The other three were made from titanium alloy $\mathrm{Ti}_{6} \mathrm{Al}_{4} \mathrm{~V}$ using additive technologies: TTM (AK Medical, Beijing, China), CONCELOC (Smith \& Nephew, Memphis, TN, USA), and ATLANT (TITAN-MED, Kyiv, Ukraine). All materials were comparable in porosity $-80 \%$ or upper. TANTALUM has an elastic modulus of $3 \mathrm{GPa}$ which is between that of cortical and cancellous bone, and similar to subchondral bone [29]. The elastic modulus of the other three materials was $12.9 \mathrm{GPa}$ for TTM [30], 4.3 GPa for CONCELOC [31], and $113 \mathrm{GPa}$ for ATLANT.

\section{Surgical procedures}

All surgeries were performed under general intramuscular anesthesia-ketamine $50 \mathrm{mg} / \mathrm{kg}$. Bilateral ovariectomies were performed in 28 animals in the OVX group according to previously described methodology [28]. For the $\mathrm{SH}$ group, the ovaries were not removed. At 3 months after ovariectomy, when osteoporotic bone changes had developed in the OVX group [28], surgery was performed in both groups (OVX and $\mathrm{SH}$ ) of rats. The skin of the lower extremities was shaved and treated with Betadine ${ }^{\circ}$ solution. From the lateral access, transcortical defects (diameter $2.5 \mathrm{~mm}$, depth $3.0 \mathrm{~mm}$ ) were created into the distal metaphysis of the left femur using a dental burr (Fig. 1a, b). The implants (TANTALUM, TTM, CONCELOC, or ATLANT) were placed into the prepared defects (Fig. 1c) by using a press-fit technique. Wounds were treated with antibiotic powder and sutured in layers.

The euthanasia of rats was performed 45 days after surgery by administering a lethal dose of anesthetic (sodium thiopental, $90 \mathrm{mg} / \mathrm{kg}$ intramuscularly). This 

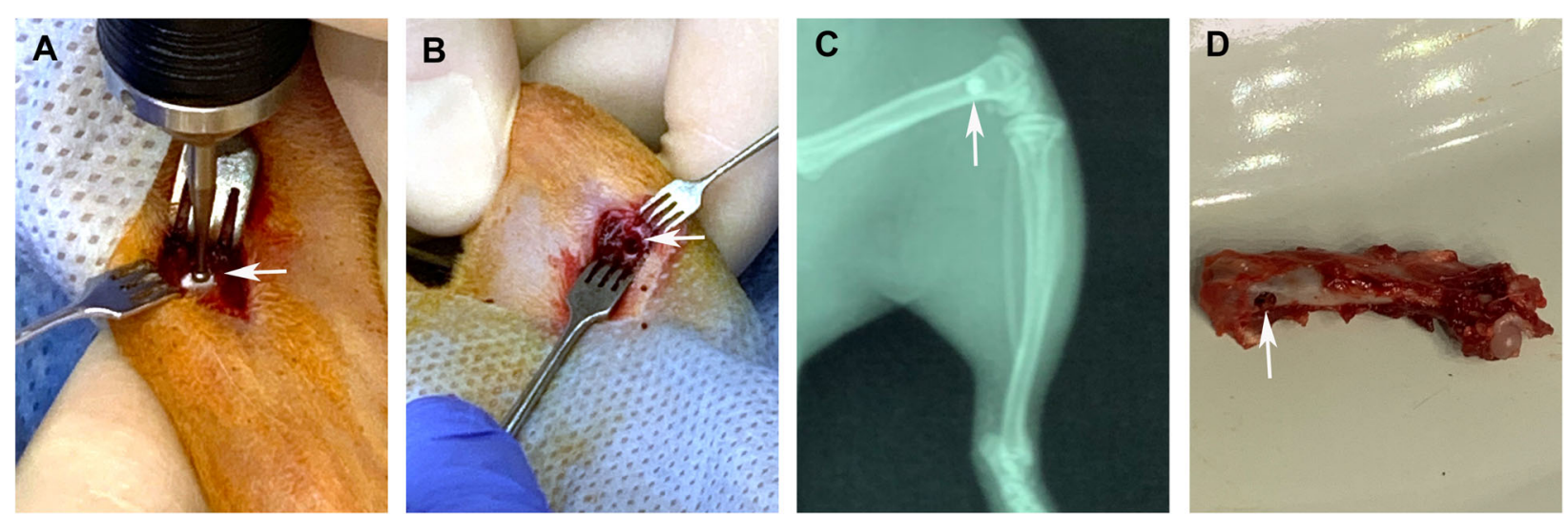

Fig. 1 Creation of a defect (arrow) in the distal rat femur (a). The created defect (arrow) (b). X-ray of the rat femur immediately after implantation with the implant placed (arrow) (c). The femur of the rat after euthanasia with an implant in the defect 45 days after implantation (arrow) (d)

observation period was chosen for the reason that other researchers conducted similar experimental studies on rats in the same period [32], as well as the results of the previous study performed by us [28], since for this period ( 45 days), the site of defect is substituted by new formed mature bone.

\section{Histological study}

After extraction, the implanted left femurs (Fig. 1d) were fixed in a solution of $10 \%$ formalin and decalcified in a $10 \%$ solution of formic acid. After decalcification, the implants were carefully removed, and the distal metaphysis of the femurs was dehydrated in alcohols of increasing concentration and a mixture of paraffin and xylene (1:1) and embedded into paraffin. Longitudinal histological sections of 5-6 $\mu \mathrm{m}$ (7 of each sample) thick were stained with hematoxylin and eosin (H\&E). The bone structure was analyzed under light microscope BX63 (Olympus, Japan) and imaged with a digital camera DP73 (Olympus).

\section{Histomorphometry}

Three sections were obtained from each femoral distal metaphysis. The percentage of peri-implant bone area (BA\%) around the implant at a distance of $500 \mu \mathrm{m}$ in the cancellous area was measured as described previously $[26,33]$. The BA\% allows us to evaluate all bone areas, not only along the perimeter of the implant, but also at a greater distance from the implant. This is especially important in osteoporosis, when the overall bone area/ mass is reduced. The measurements were made using CellSens Dimension 1.8.1 software (Olympus, 2013) for the Olympus BX-63 microscope (at a magnification rate of $\times 4$ ).

\section{Statistical analysis}

Measurement data were presented as mean \pm standard deviation (SD). Comparison of the values in the groups of OVX rats and $\mathrm{SH}$ rats was performed by using the one-way ANOVA analysis with Bonferroni post-test. To compare values between $\mathrm{OXV}$ and $\mathrm{SH}$ groups, we used unpaired $t$ test. A critical level of significance was accepted as 0.05 . The analysis was performed using the IBM SPSS Statistics 19.0 software.

\section{Results}

During histological examination at 45 days after surgery in animals of both groups, a formation of mature bone tissue with varying degrees around all the tested implants was detected.

In $\mathrm{SH}$ rats, there were bone trabeculae of lamellar structure with red and yellow bone marrow in the intertrabecular spaces. Their structure did not differ between the different types of materials evaluated.

In OVX rats in the cancellous bone defect zone (Fig. $2 a-d)$, newly formed bone trabeculae were characterized by a high density of osteocytes. These bone trabeculae shaped around the implants formed a network. At the same time, the host bone trabeculae were thin, located vertically, at a distance from each other, and did not create the trabecular network. The signs of a reorganization of the newly formed bone were detected in all groups. There were some debris structures of osteons, dilated vascular channels with the formation of connective tissue and bone marrow. In some trabeculae, destructive gaps filled with tissue fluid were observed, as well as areas without cells. In small areas on the surface of the implants, woven bone and connective tissue (Fig. 2b) was located.

In the cortex defect (Fig. 3a-d) in the OVX group, trabecular bone was observed as well. This trabecular bone was found to be remodeling and usually strongly connected with the host compact bone and forming periosteal regenerate. In the host cortex in animals of all groups, especially the section distal from the injury area, 

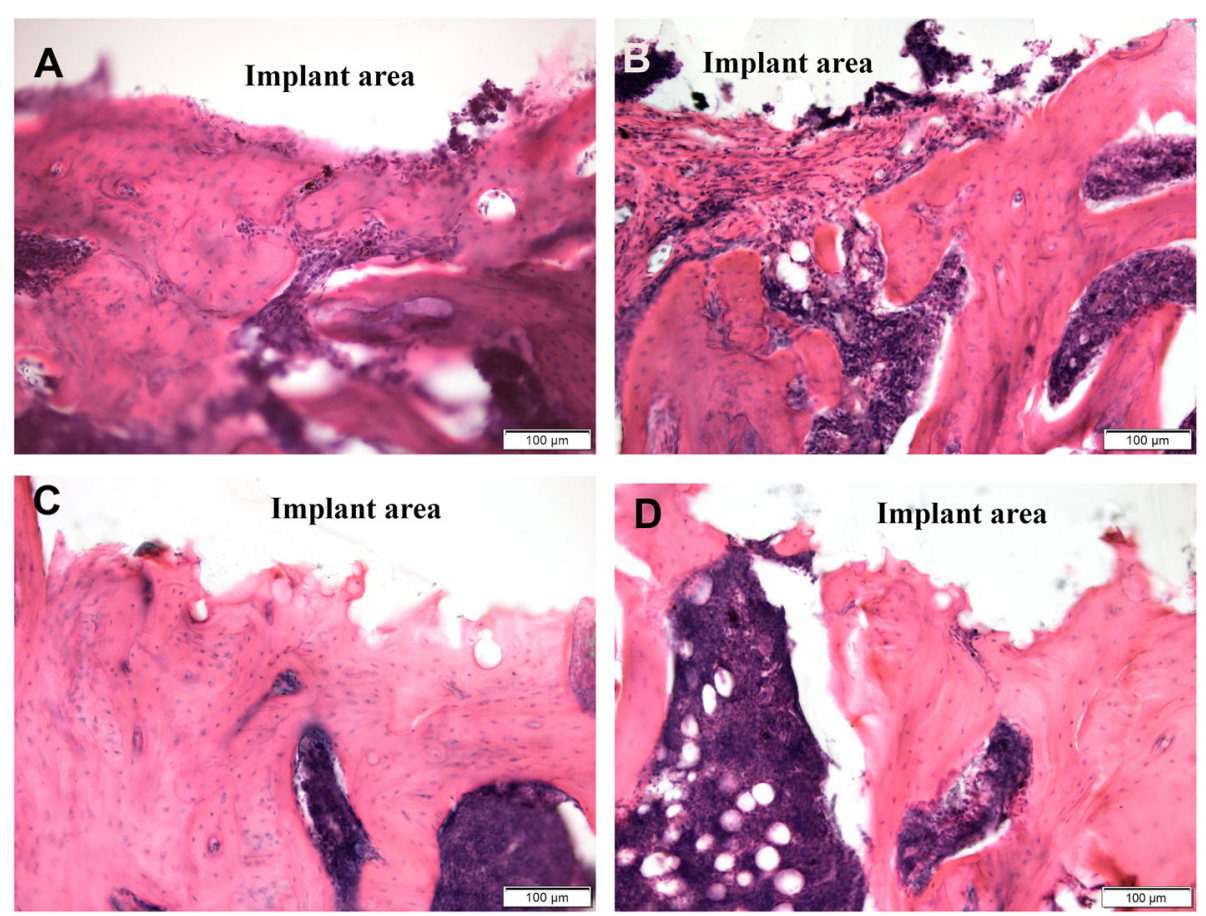

Fig. 2 Histological features of newly-formed bone in the cancellous bone defect zone in distal femoral metaphysis of the OVX rats. Forty-five days after implantation of TANTALUM (a), TTM (b), CONCELOC (c), or ATLANT (d). H\&E
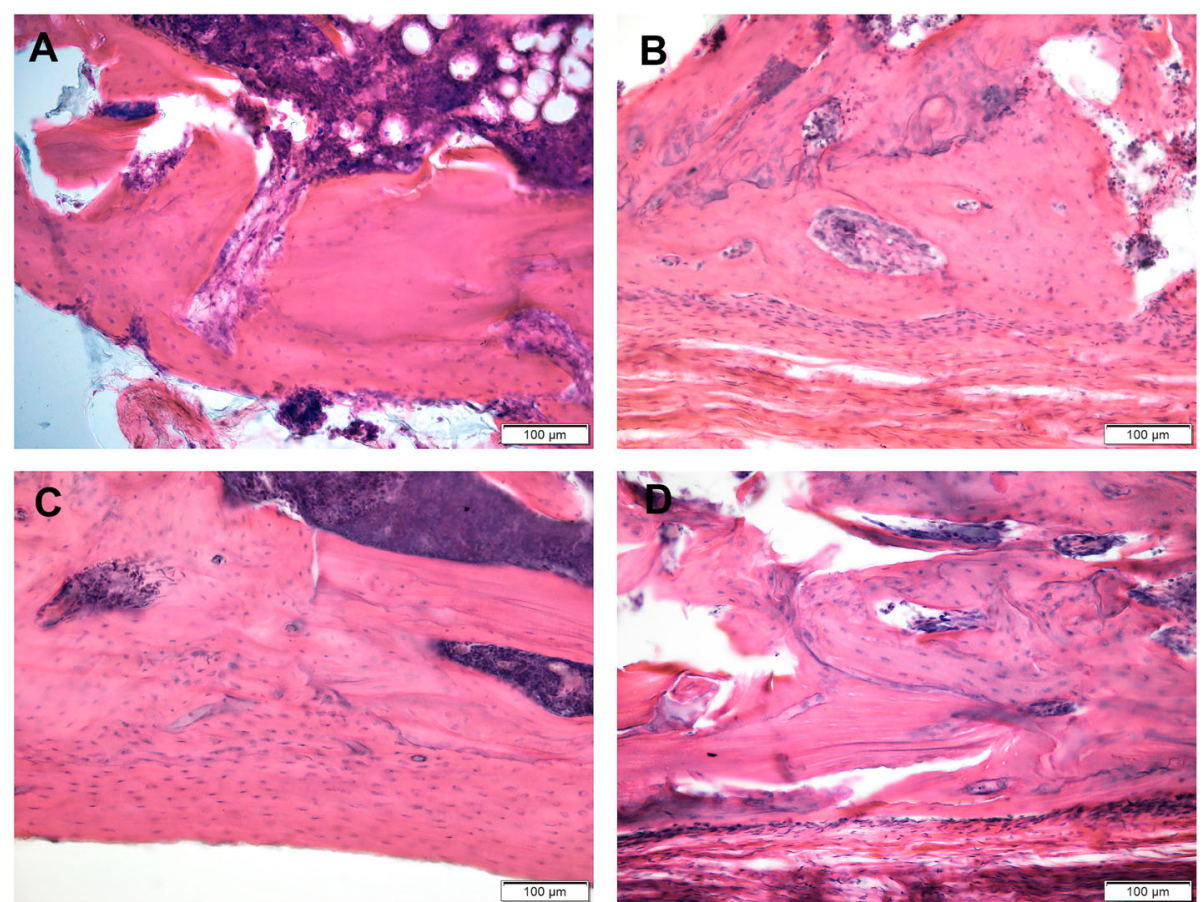

Fig. 3 Remodeling of the new-formed bone in the cortex defect zone in distal femoral metaphysis of the OVX rats. Forty-five days after implantation of TANTALUM (a), TTM (b), CONCELOC (c), or ATLANT (d). H\&E 
destructive changes in the form of a rarefaction and thinning were noted. As a result, structural bone was replaced by cancellous bone.

As a result of histomorphometry in the $\mathrm{SH}$ group, no differences in BA\% among the different implanted materials were found (Table 1).

In a series of OVX rats, the BA\% around ATLANT implants was lower by a factor of $1.5(p=0.002)$ compared to TANTALUM. The BA\% around CONCELOC and TTM specimens did not differ significantly from indicators in the OVX TANTALUM group.

In the $\mathrm{SH}$ group, the BA\% around TANTALUM and TTM was higher by a factor of $1.9(p<0.0001)$, CONCELOC by a factor of $2.8(p<0.0001)$, and ATLANT by a factor of $2.7(p<0.0001)$ compared to the OVX group (Table 1).

\section{Discussion}

In our study, carried out in an animal model, we evaluated structural features of the cancellous bone adjacent to four different porous implants: TANTALUM and three others made from titanium alloy $\mathrm{Ti}_{6} \mathrm{Al}_{4} \mathrm{~V}$ using additive technologies-TTM, CONCELOC, and ATLA NT. To evaluate their effectiveness in implantation in osteoporotic bone compared to normal bone, we used the generally accepted model of ovariectomy [24]. Our results demonstrated that the type of implant material did not affect the formation and rearrangement of the adjacent cancellous bone after 45 days in animals with normal bone quality (sham ovariectomy group). Similar results were obtained in an experiment on New Zealand rabbits: the authors did not find any differences in osseointegration quality of porous tantalum and porous titanium made by using 3D printing technology at 2, 4, and 8 weeks after implantation in the femoral lateral malleolus [34]. In another study on rabbits, the authors did not find differences in bone growth during implantation of tantalum and titanium porous implants in the femur [35]. In another experimental study on rats, no differences were found in bone formation on the implant

Table 1 BA\% around different implants implanted into distal femur metaphysis in sham-ovariectomized and ovariectomized rats (mean $\pm \mathrm{SD}$ )

\begin{tabular}{llll}
\hline $\begin{array}{l}\text { The } \\
\text { material }\end{array}$ & \multicolumn{2}{l}{ Group of rats } & \multirow{2}{*}{$\begin{array}{l}\text { Unpaired } \\
t \text { test }\end{array}$} \\
\cline { 2 - 3 } & Sham-ovariectomized & Ovariectomized & \\
\hline TANTALUM & $21.09 \pm 7.96$ & $10.89 \pm 2.47$ & $p<0.0001$ \\
TTM & $18.76 \pm 5.97$ & $9.67 \pm 4.03$ & $p<0.0001$ \\
CONCELOC & $22.67 \pm 6.88$ & $7.99 \pm 3.37$ & $p<0.0001$ \\
ATLANT & $19.87 \pm 4.92$ & $7.37 \pm 2.40^{*}$ & $p<0.0001$ \\
ANOVA & $p=0.158$ & $p=0.002$ & \\
\hline * $p<0.01$ vs TANTALUM in ovariectomized rats' group (Bonferroni post-test)
\end{tabular}

surface in the distal femur at the 12th week time point between tantalum and titanium implants [36].

For OVX rats, we set the lowest BA\% for ATLANT. In our previous in vivo study, with an osteoporosis model, we observed by way of histomorphometry and histology studies a higher level of osseointegration of trabecular tantalum implants compared to highly porous titanium implants [28]. According to in vitro studies of bone mesenchymal stromal cells of ovariectomized rats, a tantalum substrate exhibits better biocompatibility and osteoinductive properties than titanium [37]. This may contribute to better bone formation around certain implants in cases of osteoporosis. Furthermore, we found lower rates of bone area (BA\% decreased by1.9-2.8 times) in OVX rats compared to the $\mathrm{SH}$ group. The greatest differences in bone formation were found in OVX rats compared to the $\mathrm{SH}$ group with CONCELOC (by 2.8 times) and ATLANT (by 2.7 times). This may confirm the existence of differences in the osseointegration of porous implants with osteoporosis bone. An important role in achieving good long-term results during acetabular reconstruction is influenced by both a correct choice of implant and the bone quality in the periprosthetic acetabular area $[10,38]$. It has been shown that in the osteoporotic bone, the rate of migration of uncemented acetabular cups is elevated [2]. Furthermore, periprosthetic fractures may occur [39], which might lead to revision surgery due to decreased fixation of the acetabular cup due to the fragility of the adjacent bone [40]. Recently, a significant amount of porous materials from titanium alloys have been introduced for this purpose [41], an important role in the study of their biomechanical qualities is performed by experimental studies in vivo and in vitro. Current implants made from titanium alloys and tantalum have been successfully used for THA in patients with normal bone mineral density for many years [23]. However, in osteoporotic conditions under changed biomechanical conditions, the long-term survival rate may be reduced [2]. Therefore, the search for the optimal material for hip reconstruction with biomechanical properties resembling the properties of cancellous bone continues.

One of the factors that influenced the results can be Young's modulus of the materials studied. It has been clinically established that the amount of bone can decrease over a period of 14 years around the femoral stem due to the pressure placed by the implant on the bone, due to the larger Young's modulus of the implant compared to the bone's [42]. The use of porous implants from titanium alloy $\mathrm{Ti}_{6} \mathrm{Al}_{4} \mathrm{~V}$ is due to their reduced Young's modulus, which is closer in value to the cortical bone than to the spongy bone [43]. Experimentally, using finite element algorithms, it was found that a decrease in the stiffness of the material promotes bone 
growth [44]. The fact that TANTALUM has the lowest Young's modulus, which is similar in value to the spongy bone among the materials studied, may contribute to the results seen of bone formation (BA\%) around such implants in OVX rats. While the lowest BA\% in OVX rats was found in the case of implantation of ATLANT material, which had the largest Young's modulus among the studied materials. Therefore, we assume that the lowest bone formation (BA\%) found in the $\mathrm{SH}$ and OVX groups for ATLANT is due to the high modulus of elasticity of this material.

Our study is not without limitations; the main limitation of our study was the ability to only measure the bone area around the implants. However, this study shows the peculiarities of bone structure around various materials used in acetabular cup implants in an osteoporotic model in comparison with a normal bone model, which is an understudied topic.

\section{Conclusions}

Bone formation and osseointegration around the studied porous titanium and tantalum materials in the osteoporosis model were lower than in the normal bone model. There are differences in bone formation for various materials in the osteoporosis model, while in the normal bone model, differences were absent.

\section{Abbreviations}

BA\%: Percentage of peri-implant bone area; OVX: Ovariectomy group of rats; SD: Standard deviation; SH: Sham-operated control group of rats; THA: Total hip arthroplasty

\section{Acknowledgements}

Not applicable

\section{Authors' contributions}

All authors contributed to the study conception and design. Material preparation, data collection, and surgical procedures were performed by Gl and $A A B$. NA and VM performed the histological analysis. The first draft of the manuscript was written by SB, NA, and VM. The review and editing was performed by RS. All authors commented on previous versions of the manuscript. All authors read and approved the final manuscript.

\section{Funding}

Not applicable

\section{Availability of data and materials \\ Not applicable}

\section{Ethics approval and consent to participate}

Approval was obtained from the Bioethics Committee of Sytenko Institute of Spine and Joint Pathology National Academy of Medical Sciences of Ukraine, Kharkiv, Ukraine (protocol number 139 of 21 May 2018)

\section{Consent for publication}

Not applicable

\section{Competing interests}

Author RS is a paid consultant of Smith \& Nephew, , USA

\section{Author details}

${ }^{1}$ Dept of Joint Pathology, Sytenko Institute of Spine and Joint Pathology, National Academy of Medical Sciences of Ukraine, 80 Pushkinskaya St,
Kharkiv 61024, Ukraine. ${ }^{2}$ NYU Langone Medical Center, Hospital for Joint Diseases, New York, USA.

Received: 3 June 2020 Accepted: 28 July 2020

Published online: 03 August 2020

\section{References}

1. Brulc $U$, Antolič $V$, Mavčič B. Risk factors for unsuccessful acetabular press-fit fixation at primary total hip arthroplasty. Orthop Traumatol Surg Res. 2017; 103(7):993-7.

2. Finnilä S, Moritz N, SvedströM E, Alm JJ, Aro HT. Increased migration of uncemented acetabular cups in female total hip arthroplasty patients with low systemic bone mineral density. A 2-year RSA and 8-year radiographic follow-up study of 34 patients. Acta Orthop. 2016;87(1):48-54.

3. Glowacki J, Hurwitz S, Thornhill TS, Kelly M, LeBoff MS. Osteoporosis and vitamin-D deficiency among postmenopausal women with osteoarthritis undergoing total hip arthroplasty. J Bone Joint Surg Am. 2003;85(12):2371-7.

4. Mäkinen TJ, Alm JJ, Laine H, Svedström E, Aro HT. The incidence of osteopenia and osteoporosis in women with hip osteoarthritis scheduled for cementless total joint replacement. Bone. 2007:40(4):1041-7.

5. García-Cimbrelo E, Munuera L. Early and late loosening of the acetabular cup after low-friction arthroplasty. J Bone Joint Surg Am. 1992;74(8):1119-29.

6. Illgen R 2nd, Rubash HE. The optimal fixation of the cementless acetabular component in primary total hip arthroplasty. J Am Acad Orthop Surg. 2002; 10(1):43-56.

7. Kavanagh BF, Wallrichs S, Dewitz M, Berry D, Currier B, Ilstrup D, et al. Charnley low-friction arthroplasty of the hip. Twenty-year results with cement. J Arthroplasty. 1994;9(3):229-34.

8. Madey SM, Callaghan JJ, Olejniczak JP, Goetz DD, Johnston RC. Charnley total hip arthroplasty with use of improved techniques of cementing. The results after a minimum of fifteen years of follow-up. J Bone Joint Surg Am. 1997;79(1):53-64.

9. Karachalios T, editor. Bone-implant interface in orthopedic surgery: basic science to clinical applications. Springer Science \& Business Media, 2013: 342.

10. Apostu D, Lucaciu O, Berce C, Lucaciu D, Cosma D. Current methods of preventing aseptic loosening and improving osseointegration of titanium implants in cementless total hip arthroplasty: a review. J Int Med Res. 2018:46(6):2104-19.

11. Naziri Q, Issa K, Pivec R, Harwin SF, Delanois RE, Mont MA. Excellent results of primary THA using a highly porous titanium cup. Orthopedics. 2013;36(4):e390-4

12. Perticarini L, Zanon G, Rossi SM, Benazzo FM. Clinical and radiographic outcomes of a trabecular titanium ${ }^{\text {TM }}$ acetabular component in hip arthroplasty: results at minimum 5 years follow-up. BMC Musculoskelet Disord. 2015;16:375.

13. LV J, Jia Z, Li J, Wang Y, Yang J, Xiu P, et al. Electron beam melting fabrication of porous Ti6Al4V scaffolds: cytocompatibility and osteogenesis. Adv Eng Mater. 2015;17(9):1391-8.

14. Lewallen EA, Riester SM, Bonin CA, Kremers HM, Dudakovic A, Kakar S, et al. Biological strategies for improved osseointegration and osteoinduction of porous metal orthopedic implants. Tissue Eng Part B Rev. 2015;21(2):218-30.

15. De Martino I, De Santis V, Sculco PK, D'Apolito R, Poultsides LA, Gasparini G. Long-term clinical and radiographic outcomes of porous tantalum monoblock acetabular component in primary hip arthroplasty: a minimum of 15-year follow-up. J Arthroplasty. 2016;31(9 Suppl):110-4

16. Wang Q, Zhang H, Li Q, Ye L, Gan H, Liu Y, et al. Biocompatibility and osteogenic properties of porous tantalum. Exp Ther Med. 2015:9(3):780-6.

17. Banerjee S, Issa K, Kapadia BH, Pivec R, Khanuja HS, Mont MA. Systematic review on outcomes of acetabular revisions with highly-porous metals. Int Orthop. 2014;38(4):689-702.

18. Macheras GA, Lepetsos P, Leonidou AO, Anastasopoulos PP, Galanakos SP Poultsides LA. Survivorship of a porous tantalum monoblock acetabular component in primary hip arthroplasty with a mean follow-up of 18 years. J Arthroplasty. 2017;32(12):3680-4.

19. Laaksonen I, Lorimer M, Gromov K, Eskelinen A, Rolfson O, Graves SE, et al Trabecular metal acetabular components in primary total hip arthroplasty. Acta Orthop. 2018;89(3):259-64.

20. Ding $X$, Liu $X$, Chen J, Chen S. Research progress of porous tantalum in bone tissue engineering. Zhongguo Xiu Fu Chong Jian Wai Ke Za Zhi. 2018; 32(6):753-7 Chinese.

21. Vutescu ES, Hsiue P, Paprosky W, Nandi S. Comparative survival analysis of porous tantalum and porous titanium acetabular components in total hip arthroplasty. Hip Int. 2017;27(5):505-8. 
22. Wegrzyn J, Kaufman KR, Hanssen AD, Lewallen DG. Performance of porous tantalum vs. titanium cup in total hip arthroplasty: randomized trial with minimum 10-year follow-up. J Arthroplasty. 2015;30(6):1008-13.

23. Sodhi N, Khlopas A, Berliner Z, Dushaj K, Minter JE, Naylor B, et al. Survivorship and radiographic analysis of highly porous acetabular cups designed for improved osseointegration potential. Surg Technol Int. 2019; 34:425-9.

24. Li Z, Müller R, Ruffoni D. Bone remodeling and mechanobiology around implants: Insights from small animal imaging. J Orthop Res. 2018;36(2):58493.

25. Freitag L, Günther C, Eberli U, Fürst A, Zeiter S, Stadelmann VA. Relative effects of age on implant integration in a rat model: a longitudinal in vivo microct study. J Orthop Res. 2019;37(3):541-52.

26. Li Y, He S, Hua Y, Hu J. Effect of osteoporosis on fixation of osseointegrated implants in rats. J Biomed Mater Res B Appl Biomater. 2017:105(8):2426-32

27. Li Z, Kuhn G, von Salis-Soglio M, Cooke SJ, Schirmer M, Müller R, et al. In vivo monitoring of bone architecture and remodeling after implant insertion: the different responses of cortical and trabecular bone. Bone. 2015;81:468-77.

28. Bondarenko S, Dedukh N, Filipenko V, Akonjom M, Badnaoui AA, Schwarzkopf R. Comparative analysis of osseointegration in various types of acetabular implant materials. Hip Int. 2018;28(6):622-8.

29. Zhang Y, Ahn PB, Fitzpatrick DC, Heiner AD, Poggie RA, Brown TD. Interfacial frictional behavior: cancellous bone, cortical bone, and a novel porous tantalum biomaterial. J Musculoskelet Res. 1999;3(04):245-51.

30. Yang J, Cai H, Lv J, Zhang K, Leng H, Sun C, et al. In vivo study of a selfstabilizing artificial vertebral body fabricated by electron beam melting. Spine (Phila Pa 1976). 2014;39(8):E486-92.

31. Smith \& Nephew Research report. OR-14-106.

32. Handool KO, Ibrahim SM, Kaka U, Omar MA, Abu J, Yusoff MSM, Yusof LM. Optimization of a closed rat tibial fracture model. J Exp Orthop. 2018;5(1):13.

33. Dempster DW, Compston JE, Drezner MK, Glorieux FH, Kanis JA, Malluche H, et al. Standardized nomenclature, symbols, and units for bone histomorphometry: a 2012 update of the report of the ASBMR Histomorphometry Nomenclature Committee. J Bone Miner Res. 2013;28(1):2-17.

34. Su KX, Ji P, Wang H, Li LL, Su LZ, Wang C. In vivo study of 3D printed porous tantalum implant on osseointegration. Hua Xi Kou Qiang Yi Xue Za Zhi. 2018;36(3):291-5 Chinese.

35. Wang H, Su K, Su L, Liang P, Ji P, Wang C. Comparison of 3D-printed porous tantalum and titanium scaffolds on osseointegration and osteogenesis. Mater Sci Eng C Mater Biol Appl. 2019;104:109908.

36. Bandyopadhyay A, Mitra I, Shivaram A, Dasgupta N, Bose S. Direct comparison of additively manufactured porous titanium and tantalum implants towards in vivo osseointegration. Addit Manuf. 2019;28:259-66.

37. Lu MM, Wu PS, Guo XJ, Yin LL, Cao HL, Zou D. Osteoinductive effects of tantalum and titanium on bone mesenchymal stromal cells and bone formation in ovariectomized rats. Eur Rev Med Pharmacol Sci. 2018;22(21):7087-104.

38. Gao X, Fraulob M, Haïat G. Biomechanical behaviours of the bone-implant interface: a review. J R Soc Interface. 2019;16(156):20190259.

39. Giaretta S, Momoli A, Porcelli G, Micheloni GM. Diagnosis and management of periprosthetic femoral fractures after hip arthroplasty. Injury. 2019; 50(Suppl 2):S29-33.

40. Aro HT, Alm JJ, Moritz N, Mäkinen TJ, Lankinen P. Low BMD affects initial stability and delays stem osseointegration in cementless total hip arthroplasty in women: a 2-year RSA study of 39 patients. Acta Orthop. 2012;83(2):107-14.

41. Migaud H, Common H, Girard J, Huten D, Putman S. Acetabular reconstruction using porous metallic material in complex revision total hip arthroplasty: a systematic review. Orthop Traumatol Surg Res. 2019;105(1S):S53-61.

42. Bodén HS, Sköldenberg OG, Salemyr MO, Lundberg HJ, Adolphson PY Continuous bone loss around a tapered uncemented femoral stem: a longterm evaluation with DEXA. Acta Orthop. 2006:77(6):877-85.

43. Arabnejad S, Johnston B, Tanzer M, Pasini D. Fully porous 3D printed titanium femoral stem to reduce stress-shielding following total hip arthroplasty. J Orthop Res. 2017;35(8):1774-83.

44. Cheong VS, Fromme P, Mumith A, Coathup MJ, Blunn GW. Novel adaptive finite element algorithms to predict bone ingrowth in additive manufactured porous implants. J Mech Behav Biomed Mater. 2018:87:230-9.

\section{Publisher's Note}

Springer Nature remains neutral with regard to jurisdictional claims in published maps and institutional affiliations.

\section{Ready to submit your research? Choose BMC and benefit from:}

- fast, convenient online submission

- thorough peer review by experienced researchers in your field

- rapid publication on acceptance

- support for research data, including large and complex data types

- gold Open Access which fosters wider collaboration and increased citations

- maximum visibility for your research: over $100 \mathrm{M}$ website views per year

At BMC, research is always in progress.

Learn more biomedcentral.com/submissions 